\title{
Clinical and Biochemical Heterogeneity in an Italian Family with CPT II Deficiency due to Ser 113 Leu Mutation
}

\author{
Mubeen F. Rafay, E. Gordon Murphy, J. Denis McGarry, \\ Petra Kaufmann, Salvatore DiMauro, Ingrid Tein
}

\begin{abstract}
Background: Carnitine palmitoyltransferase II (CPT II) deficiency is an autosomal recessive disorder which presents with recurrent myoglobinuria. Heterozygotes are usually asymptomatic. Methods: We correlate the clinical, biochemical and molecular features of a family in which the proband is homozygous for CPT II deficiency, due to the common Ser 113 Leu mutation. Results: The 20-year-old female proband presented at age three years with episodic myalgia and myoglobinuria, elevated creatine kinase (CK) of $3600 \mathrm{IU} / \mathrm{L}$ and had a $33 \%$ residual CPT II activity in cultured skin fibroblasts. Her 25-year-old dizygotic twin brothers presented with muscle stiffness following prolonged exercise but no overt pigmenturia and had interictal CKs up to 662 IU/L. Her parents and a 13year-old brother are asymptomatic. An elder sister, not investigated, had recurrent pigmenturia and died at eight years with myoglobinuria. Molecular analysis revealed that the proband is homozygous for the Ser 113 Leu mutation. Her parents are heterozygotes with CPT II activities of $55 \%$ to $70 \%$. Her younger brother is normal with $83 \%$ activity. The symptomatic twin brothers are heterozygous but demonstrated unexpectedly low CPT II activities of 40\%, which may explain their phenotype. Conclusion: We postulate that there may be genetic, environmental and sex hormonal factors accounting for this manifesting heterozygosity and biochemical heterogeneity in CPT II deficiency.
\end{abstract}

RÉSUMÉ: Hétérogénéité clinique et biochimique chez une famille italienne porteuse d'un déficit en CPT II dû à une mutation ser 113 leu. Introduction: Le déficit en carnitine palmitoyltransférase II (CPT II) est une maladie récessive autosomique ayant comme mode de présentation une myoglobinurie récurrente. Les hétérozygotes sont habituellement asymptomatiques. Méthodes: Nous décrivons les caractéristiques cliniques, biochimiques et moléculaires d'une famille dont le cas index est porteur d'un déficit en CPT II à l'état homozygote dû à une mutation fréquente, une substitution ser 113 leu. Résultats: Le cas index, une patiente maintenant âgée de 20 ans, a été vue pour la première fois à l'âge de trois ans parce qu'elle présentait des épisodes de myalgie et de myoglobinurie et un taux élevé de créatine-phosphokinase (CPK) à 3600 U/L. L'activité résiduelle de la CPT II était de 33\% dans ses fibroblastes cutanés en culture. Ses deux frères âgés de 25 ans, des jumeaux fraternels, avaient de la raideur musculaire après un exercice prolongé, sans myoglobinurie évidente et un taux interictal de CPK qui atteignait 662 U/L. Ses parents et un frère âgé de 13 ans sont asymptomatiques. Une sœur aînée, qui n'a pas été investiguée, avait une pigmenturie récurrente et elle est décédée à 8 ans d'une myoglobinurie. L'analyse moléculaire a montré une mutation ser 113 leu à l'état homozygote chez le cas index. Ses parents sont hétérozygotes et leur activité CPT II varie de $55 \%$ à $70 \%$. Son jeune frère est normal et l'activité CPT II chez-lui est de $83 \%$. Cependant, l'activité CPT II est singulièrement basse à $40 \%$ chez ses deux frères jumeaux hétérozygotes qui sont symptomatiques, ce qui peut expliquer leur phénotype. Conclusion: Nous postulons que ce tableau clinique et cette hétérogénéité chez des hétérozygotes pour un déficit en CPT II pourraient être dus à des facteurs génétiques, environnementaux ou en relation avec les hormones sexuelles.

Can. J. Neurol. Sci. 2005; 32: 316-320

Carnitine palmitoyltransferase (CPT) deficiency is one of the most common autosomal recessive inherited disorders of lipid metabolism, affecting skeletal muscle. ${ }^{1,2}$ The CPT II enzyme is located on the inside of the inner mitochondrial membrane. ${ }^{3,4}$ It participates in the transfer of long chain fatty acids from the cytosol into the mitochondria by converting palmitoylcarnitine and Coenzyme A (CoA) to palmitoylCoA and palmitoylCoA and carnitine. Fatty acid oxidation in the liver is responsible for the generation of ketones, which are essential for cerebral energy metabolism during fasting hypoglycemia. ${ }^{5}$ Fatty acid oxidation is important in all tissues with high bioenergetic demands such as muscle, nerve, heart, small bowel and kidney ${ }^{6}$ and serves as a primary energy source in resting muscle and during prolonged aerobic exercise ${ }^{7}$. It is also important in shivering thermogenesis.

The CPT II protein is a homotetramer encoded by the CPT II gene, which is located on chromosome $1 \mathrm{p} 32 .{ }^{8}$ The gene spans

From the Department of Pediatrics, The Hospital for Sick Children (MFR, EGM, IT) and Department of Pathobiology and Laboratory Medicine (IT), University of Toronto, Toronto, Ontario; Department of Internal Medicine (JDM (deceased)), Southwestern Medical Centre, Dallas, Texas, USA; Department of Neurology (PK, SD), Columbia University, New York, New York, USA

Received March 29, 2004. AcCePted in Final Form MarCh 17, 2005. Reprint requests to: Mubeen F. Rafay, Division of Neurology, Hospital for Sick Children, 555 University Avenue, Toronto, ON M5G 1X8 Canada 
approximately $20 \mathrm{~kb}$ and is composed of five exons. ${ }^{8,9}$ More than 39 mutations have been identified; however, the Serine 113 Leucine mutation is the most common, accounting for approximately $60 \%$ of the mutant CPT II alleles, and is due to a C-to-T transition at nucleotide $439 .{ }^{10}$

Carnitine palmitoyltransferase II deficiency (OMIM \#600650) is clinically heterogeneous and has two wellrecognized and distinct clinical phenotypes. ${ }^{11-13}$ The benign classic muscular form (OMIM \#255110) is the most common presentation and is seen in young adults. It typically presents with recurrent episodes of muscle pain, weakness, and paroxysmal myoglobinuria with elevated serum creatine kinase (CK) and, in some cases, acute renal failure. These crises are triggered by prolonged exercise, cold exposure, or infection with fever and are associated with a decreased residual CPT II activity of approximately $20-25 \%$ in cultured skin fibroblasts. The severe infantile, usually lethal, hepatocardiomuscular form (OMIM \#600649) is uncommon and presents in infants with hepatomegaly, myopathy, cardiomyopathy and episodic hypoketotic, hypoglycemic encephalopathy. There is laboratory evidence of elevated serum CK, low total serum carnitine concentration with elevated long chain acylcarnitines, dicarboxylic aciduria and residual CPT II activity as low as $10 \%$ in fibroblasts. Patients are primarily at risk when exposed to precipitating factors that stress fatty acid oxidation, such as fasting, infectious illness, vomiting, prolonged exercise, cold exposure and in some cases, emotional stress. The mainstay of therapy is, therefore, preventative with the avoidance of precipitating factors. In addition, a high carbohydrate, low fat diet and frequent feeding decrease the risk of rhabdomyolysis in CPT II deficient patients. We now report an Italian family, with CPT II deficiency due to the Serine 113 Leucine (Ser 113 Leu) Leu mutation, which presents with clinical and biochemical heterogeneity.

\section{Case Report}

The proband is a 20 -year-old girl of Italian descent, who presented at the age of three years, with an acute episode of severe myalgia, muscle weakness involving the extremities and neck, as well as respiratory muscles requiring ventilatory assistance and myoglobinuria precipitated by an acute upper respiratory tract infection due to the Epstein Barr virus. On general examination, she appeared pale and ill and was febrile. On neurologic examination, she was alert and oriented. Her cranial nerve examination was normal. On motor examination, she was noted to have significant weakness, with an inability to lift her head from the bed. Manual motor testing (Medical Research Council standard, MRC scale, M1--M5) ${ }^{14}$ revealed $^{14}$ grade 3/5 weakness in the neck flexors and extensors and grade 4/5 weakness in the remaining muscle groups. Muscle tenderness was noted in all major muscle groups. Muscle tone and deep tendon reflexes were normal in both upper and lower extremities. Plantar reflexes were down going bilaterally. Cerebellar coordination, sensation and autonomic functions were normal.

Her biochemical investigations at that time revealed a serum $\mathrm{CK}>$ 3600 IU/L (normal <150), markedly elevated transaminases and myoglobin in the urine. Serum electrolytes, urea, creatinine, glucose, ammonia and lactate were normal. Serum and urine amino acids and organic acids were also normal. Electrocardiogram and chest X-ray were normal. Electromyography revealed mild myopathic discharges. She was managed with bed rest and an intravenous glucose infusion (10mg/kg/min glucose). All her biochemical abnormalities normalized and she recovered fully in 14 days, without residual weakness. Following recovery, muscle biopsy of the right triceps demonstrated type 1 fibre predominance and no evidence of necrosis, degeneration, regeneration, atrophy or hypertrophy. The Oil-Red-O, Gomori trichrome, succinic dehydrogenase (SDH) and cytochrome oxidase (COX) stains were normal. Electron microscopy revealed normal mitochondria and no accumulation of lipid. At the age of 12 years, she suffered another episode of myalgia and myoglobinuria, precipitated by a streptococcal throat infection. Her neurological examination at that time was characterized by muscle tenderness and minimal weakness. Enzyme assay of cultured skin fibroblasts demonstrated a 33\% residual CPT II activity, which supported the diagnosis of CPT II deficiency. Molecular analysis identified the proband as homozygous for the Serine 113 Leucine mutation. She has been managed according to standard CPT II management guidelines with a high carbohydrate and low fat diet, frequent feedings, as well as the avoidance of precipitating factors, such as fasting, prolonged exercise, cold exposure and infectious illness with fever and vomiting. Since then she has experienced only minor episodes of myalgia with viral infections, but without overt pigmenturia or weakness. Following the management guidelines with carbohydrate loading prior to and at regular intervals during exercise (e.g. every 15 minutes), her exercise tolerance has improved markedly. She is able to exercise for sequential 15 minute periods of time, followed by brief rest periods accompanied by carbohydrate loads, for a total duration of 30 minutes at a time during gymnastics class at school and has not suffered from subsequent muscle pain, stiffness or weakness. Her neurological examination between acute episodes has remained entirely normal. In addition, her interictal serum $\mathrm{CK}$ and plasma carnitine concentrations are normal.

Her parents are consanguineous and originate from Calabria, Italy. Both parents are clinically asymptomatic with normal neurological examinations and are physically active at work with an exercise tolerance for mild-moderate intensity exercise of more than four hours duration at a time. The proband's 25 -year-old brothers, who are nonidentical twins, are also physically active and participate in regular recreational sports and have experienced milder symptomatology. They have both noticed exertional myalgia, characterized as muscle stiffness in the quadriceps, hamstrings and peroneal muscles, following $1-1.5$ hours of prolonged exercise, during sports activities such as soccer. There has been no apparent aggravation of their muscle pain with cold exposure or infections. They have also experienced episodes of lightheadedness after periods of fasting in the past. Both had interictal serum CKs up to $662 \mathrm{IU} / \mathrm{L}$. They have had no acute episodes of myoglobinuria or hypoglycemic encephalopathy. Both brothers have normal neurological examinations and have excellent muscle power when compared to their peers. An older sister had experienced recurrent episodes of pigmenturia and myalgia during the first three years of her life, all precipitated by infection with fever. She was then reportedly well between the ages of three to eight years. However, at eight years of age, while on a trip to Europe, she suffered another febrile illness associated with 12 hours of vomiting with fasting, and suffered a final episode of pigmenturia, muscle weakness and acute renal failure and died during this episode. The youngest brother is 13 years old and is entirely asymptomatic with a normal neurological examination.

\section{Materials ANd Methods}

All studies were performed with the approval of the Institutional Review Board of the Hospital for Sick Children in 
Toronto. Cultured skin fibroblasts from the proband and her family and from normal controls were grown to confluence in alpha-MEM medium with $10 \%$ fetal calf serum. CPT I and CPT II activities were assayed in cultured skin fibroblasts in the laboratory of Dr. J. Denis McGarry (Southwestern Medical Centre, University of Texas, Dallas) by a modification of the method of Declercq et al. ${ }^{15}$

Genomic DNA was extracted according to standard protocols from cultured skin fibroblasts or peripheral leukocytes of the proband and her relatives and from ten normal controls without CPT II deficiency. The DNA was screened for the four reported missense mutations associated with the typical, adult form of CPT II deficiency, namely the S113L mutation which appears to be common among both European and American patients, ${ }^{10,16}$ and three rare mutations $\mathrm{R} 631 \mathrm{C}, \mathrm{P} 50 \mathrm{H}$ and D553N. The four mutations were screened by polymerase chain reaction (PCR) amplification and restriction enzyme digestion, using primer sets and protocols as previously described. . $^{9,10,16,17}$

\section{RESULTS}

Enzyme activities: All members of the family had entirely normal fibroblast CPT I activities compared to controls. On analysis of fibroblast CPT II activities, the index patient had a residual CPT II activity of 0.123 nmoles $/ \mathrm{min} / \mathrm{mg}$ fibroblast homogenate (controls $=0.364 \pm 0.009 ; n=20$ ); the $33 \%$ residual activity suggests that she is homozygous mutant for the CPT II gene defect. The CPT II activities in nmoles $/ \mathrm{min} / \mathrm{mg}$ fibroblast homogenate were 0.252 in her mother (70\% residual), 0.199 in her father $(55 \%$ residual), 0.146 in her fraternal twin brothers (40\% residual), and 0.303 in her youngest brother $(83 \%$ residual). The $70 \%$ and $55 \%$ residual activities in her mother and father, respectively, are consistent with their clinically asymptomatic heterozygous state. The $40 \%$ residual CPT II activity in her twin brothers is somewhat inconsistent with their mild clinical phenotype. The $83 \%$ residual CPT II activity in the youngest brother suggests that he is homozygous normal for the gene.

Mutation Analysis: Molecular analysis of the DNA by the PCR and restriction fragment length polymorphism identified a missense mutation, Serine 113 Leucine, in the CPT II gene of this pedigree. The index patient is homozygous mutant for this

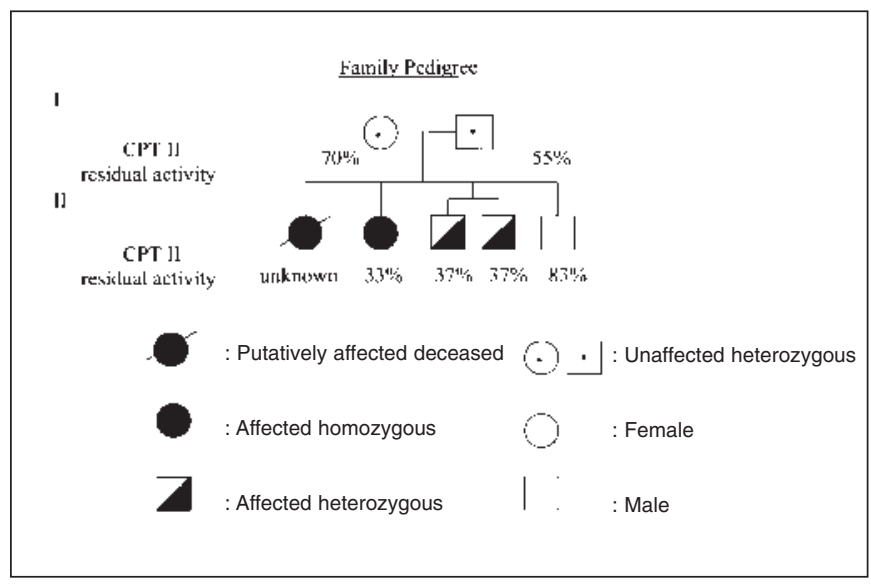

Figure: Pedigree of the family with CPT II deficiency.

mutation. Her asymptomatic parents and her symptomatic twin brothers are heterozygous. Her asymptomatic younger brother is homozygous normal for this gene. Her deceased elder sister was never investigated for CPT II deficiency but was likely homozygous mutant given her early onset and severe presentation (Figure and Table).

\section{Discussion}

Carnitine palmitoyltransferase II deficiency is an autosomal recessive disorder of lipid metabolism. The classic adult muscular form of CPT II deficiency manifests in homozygous individuals with episodic muscle pain, weakness and myoglobinuria precipitated by prolonged exercise, fasting, cold exposure or infection with fever. ${ }^{1}$ Heterozygotes are usually, though not always, asymptomatic. We found significant biochemical heterogeneity in this Italian family with CPT II deficiency. Biochemical and molecular analysis of the family showed that the index patient, who presented with the typical clinical features of adult CPT II deficiency, is homozygous for the Ser 113 Leu mutation and has a somewhat higher than expected residual CPT II activity of $33 \%$ in cultured skin

Table 1: Biochemical Phenotype and Molecular Genotype of Affected Proband and Family

\begin{tabular}{|c|c|c|c|c|c|c|}
\hline & $\begin{array}{l}\text { Female } \\
\text { Proband }\end{array}$ & $\begin{array}{c}\text { Twin } \\
\text { Brother A }\end{array}$ & $\begin{array}{c}\text { Twin } \\
\text { Brother B }\end{array}$ & Father & Mother & $\begin{array}{c}\text { Youngest } \\
\text { Brother }\end{array}$ \\
\hline $\begin{array}{l}\text { CPT II activity } \\
\text { (controls }=0.364 \pm 0.009 \\
\text { nmoles } / \mathrm{min} / \mathrm{mg} \text { fibroblasts) }\end{array}$ & 0.123 & 0.146 & 0.146 & 0.199 & 0.252 & 0.303 \\
\hline$\%$ residual CPT II activity & 33 & 40 & 40 & 55 & 70 & 83 \\
\hline Ser 113 Leu mutation & $+/+$ & $+/-$ & $+/-$ & $+/-$ & $+/-$ & $-1-$ \\
\hline
\end{tabular}


fibroblasts. Her parents, who are asymptomatic, are heterozygous for the Ser113Leu mutation and have intermediate residual CPT II activities of 55-70\%, consistent with their heterozygous state. Her older dizygotic twin brothers were found to be heterozygous for this mutation but demonstrated unexpectedly low residual CPT II activities of $40 \%$ and were mildly symptomatic. Their low residual CPT II activity is similar to that of their homozygous mutant sister (index patient) and may explain their mild clinical phenotype.

Another notable observation is the relatively higher residual CPT II activities in the female members of this family. The index patient is homozygous mutant but the $33 \%$ residual fibroblast CPT II activity is higher than expected in the classic adult muscular form of CPT II deficiency, where residual activity is usually $20-25 \% .{ }^{11,12}$ In addition, though both parents are heterozygotes by molecular analysis, the mother has higher residual CPT II activity (70\%) than the father (55\%). Conversely, the symptomatic twin brothers have lower residual CPT II activities than expected for their heterozygous mutant state, and this may explain their clinical symptomatology. It is possible that sex-related factors contribute to the relatively lower residual CPT II activities seen in the male members of this family.

Clinical heterogeneity in CPT II deficiency has been previously reported in the literature and has been largely attributed to differences in the severity of the mutations in the CPT II gene, of which at least 39 have been identified to date. ${ }^{11,16,18}$ For example, the Ser-113-Leu substitution (adult form) was shown to result in a $20 \%$ residual CPT II activity in fibroblasts, without significant impairment of long chain fatty acid (LCFA) oxidation whereas the Tyrosine-628-Serine substitution (severe infantile form) resulted in a $10 \%$ residual CPT II activity, markedly impairing LCFA oxidation. ${ }^{11}$ Thuillier et $\mathrm{al}^{18}$ analyzed a cohort of 20 CPT II-deficient patients affected either with the severe infantile (seven patients) or with the adultonset forms (13 patients) of the disease and identified 13 CPT II mutations, including five novel ones (R124Q, N146T, R161W, D328G and D608H). Based on the consequences of the different mutations on CPT II activity and on LCFA oxidation, they concluded that both the type and the site of the mutations, together with one or more additional genetic factors that remain to be identified, could modulate the LCFA flux and thereby the severity of the clinical presentation.

Compound heterozygosity for different CPT II mutations has also been postulated. However, in the present family all individuals have CPT II deficiency due to the same gene defect. Marked clinical heterogeneity with the same homozygous Ser113-Leu substitution has been previously reported in a brother and sister, children of a consanguineous marriage, and in their first cousins, also the products of a consanguineous marriage. ${ }^{19}$ The proband, a male, suffered from typical adult CPT II deficiency with recurrent myoglobinuria and his sister was less severely affected with muscle stiffness and dark urine following prolonged exercise. One of their homozygous mutant female first cousins was relatively asymptomatic with the exception of reduced tolerance to prolonged exercise and responded well to carbohydrate ingestion. A second female first cousin, who was not tested for CPT II deficiency, died at 16 years of age during a severe episode of myoglobinuria. Different clinical manifestations in three relatives with the same heterozygous gene defect (R503C) have also been reported. ${ }^{20}$ The proband in this family, a 54-year-old woman, had a 35-year history of progressive weakness with residual CPT II activities of $47 \%$ in lymphoblasts, $43 \%$ in cultured skin fibroblasts and $13 \%$ in skeletal muscle. Her heterozygous son had a lifelong history of myopathic symptoms while his heterozygous grandfather had only mild weakness during childhood.

Our data suggest that the differences in clinical phenotype in heterozygotes with the same CPT II gene defect, may be due to various factors influencing residual CPT II activity including an additional single gene defect carrier state in another fatty acid oxidation enzyme, additional undetected mutations in the CPT II gene, modifying genes within the same family, a variable exposure to precipitating factors, and perhaps the influence of sex hormones.

We conclude that heterozygotes for the Ser 113 Leu mutation are at risk for clinical symptomatology and that this genotype may be associated with significant biochemical heterogeneity in residual CPT II activity. The clinical phenotype appears to correlate with the degree of residual CPT II activity. Finally, the same genotype may have variable phenotypic expression related to additional genetic or environmental factors.

\section{ACKNOWLEDGEMENTS}

This work was supported by an operating grant from the Physicians' Services Incorporated Foundation of Ontario.

\section{REFERENCES}

1. DiMauro S, Papadimitriou A. Carnitine palmitoyltransferase deficiency. In: Engel AG, Banker BQ, (Eds). Myology (1st ed.) New York: McGraw-Hill, 1996: 1697-1708.

2. Tonin P, Lewis P, Servidei S, DiMauro S. Metabolic causes of myoglobinuria. Ann Neurol 1990; 27: 181-185.

3. McGarry JD, Brown NF. The mitochondrial carnitine palmitoyltransferase system. From concept to molecular analysis. Eur J Biochem 1997; 244: 1-14.

4. Murthy MS, Pande SV. Some differences in the properties of carnitine palmitoyltransferase activities of the mitochondrial outer and inner membranes. Biochem J 1987; 248:727-733.

5. Cahill GF Jr. Starvation in man. N Engl J Med 1970; 282: 668-675.

6. Stanley CA. New genetic defects in mitochondrial fatty acid oxidation and carnitine deficiency. Adv Pediatr 1987; 34: 59-88.

7. Felig P, Wahren J. Fuel homeostasis in exercise. N Engl J Med 1975; 293: 1078-1084.

8. Gellera C, Verderio E, Floridia G, et al. Assignment of the human carnitine palmitoyltransferase II gene (CPT 1) to chromosome 1p32. Genomics 1994; 24: 195-197.

9. Verderio E, Cavadini P, Montermini L, et al. Carnitine palmitoyltransferase II deficiency: structure of the gene and characterization of two novel disease-causing mutations. Hum Mol Genet 1995; 4: 19-29.

10. Taroni F, Verderio E, Dworzak F, et al. Identification of a common mutation in the carnitine palmitoyltransferase II gene in familial recurrent myoglobinuria patients. Nat Genet 1993; 4: 314-320.

11. Bonnefont J-P, Taroni F, Cavadini P, et al. Molecular analysis of carnitine palmitoyltransferase II deficiency with hepatocardiomuscular expression. Am J Hum Genet 1996; , 58: 971-978.

12. Demaugre F, Bonnefont J-P, Colonna M, et al. Infantile form of carnitine palmitoyl-transferase II deficiency with hepatomuscular symptoms and sudden death. Physiopathological approach to carnitine palmitoyltransferase II deficiencies. J Clin Invest 1991; 87: 859-864. 
13. Demaugre F, Bonnefont JP, Mitchell G, et al. Hepatic and muscular presentations of carnitine palmitoyl transferase deficiency: two distinct entities. Pediatr Res 1988; 24: 308-311.

14. Medical Research Council: Aids to the examination of the peripheral nervous system. Memorandum No.45. Her Majesty's Stationary Office, 1976.

15. Declercq PE, Falck JR, Kuwajima M, et al. Characterization of the mitochondrial carnitine palmitoyltransferase enzyme system. I. Use of inhibitors. J Biol Chem 1987; 262: 9812-9821.

16. Kaufmann P, El-Schahawi M, DiMauro S. Carnitine palmitoyltransferase II deficiency: diagnosis by molecular analysis of blood. Mol Cell Biochem 1997; 174: 237-239.

17. Taroni F, Verderio E, Fiorucci S, et al. Molecular characterization of inherited carnitine palmitoyltransferase II deficiency. Proc Natl Acad Sci U S A 1992; 89: 8429-8433.
18. Thuillier L, Rostane H, Droin V, et al. Correlation between genotype, metabolic data, and clinical presentation in carnitine palmitoyltransferase 2 (CPT2) deficiency. Hum Mutat 2003; 21: 493-501.

19. Handig I, Dams E, Taroni F, et al. Inheritance of the S113L mutation within an inbred family with carnitine palmitoyltransferase enzyme deficiency. Hum Genet 1996; 97: 291-293.

20. Vladutiu GD, Bennett MJ, Smail D, et al. A variable myopathy associated with heterozygosity for the R503C mutation in the carnitine palmitoyltransferase II gene. Mol Genet Metab 2000; 70: $134-141$. 